\title{
Weather Factors Associated with Development of Sorghum Ergot in the Texas Panhandle
}

\author{
F. Workneh and C. M. Rush, Texas Agricultural Experiment Station, Bushland 79012
}

\begin{abstract}
Workneh, F., and Rush, C. M. 2006. Weather factors associated with development of sorghum ergot in the Texas Panhandle. Plant Dis. 90:717-722.

Since its first introduction in 1997, sorghum ergot, caused by Claviceps africana, has been observed yearly in the Texas Panhandle, where it has caused occasional epidemics in hybrid-seed production fields. To determine the effect of weather factors on ergot severity, inoculation experiments were conducted in 2003 and 2004 using sequentially planted sorghum plants. Sorghum flowers were inoculated with three inoculum concentrations $\left(1 \times 10^{4}, 1 \times 10^{5}\right.$, or $1 \times 10^{6}$ spores $/ \mathrm{ml}$ ) prepared from infected sorghum panicles producing fresh honeydew. Each year, inoculations were conducted several times during sorghum flowering periods so that time of inoculations would coincide with different weather conditions. Weather variables (temperature, relative humidity, wind speed, precipitation, and radiation) were collected using an onsite weather station. Infected and uninfected florets were counted 8 to 13 days after inoculation, and the percentage of infected florets per sorghum panicle (severity) was determined. In both years, temperature and relative humidity were the predominant factors responsible for variations in sorghum ergot severity with all inoculum densities. Relationship between ergot severity and each of the two variables depended on inoculum density. Measurable infection occurred at a maximum temperature of $34^{\circ} \mathrm{C}$ with $1 \times 10^{6}$ spores $/ \mathrm{ml}$, while there was little or no infection at $30^{\circ} \mathrm{C}$ with $1 \times 10^{4}$ spore $/ \mathrm{ml}$. Cumulative departures from minimum relative humidity and maximum temperature infection thresholds $12,18,24,36,48$, and $72 \mathrm{~h}$ after inoculation were calculated and regressed against ergot severity for each inoculum level. Cumulative departures of hourly temperature and relative humidity from maximum temperature and minimum relative humidity infection thresholds 18 and $24 \mathrm{~h}$ after inoculation were best related to sorghum ergot severity $\left(R^{2}\right.$ $=89$ and 91; $P<0001$, respectively). Models based on these two time-durations then were used in predicting a regional site-specific ergot severity potential using radar-estimated rainfall.
\end{abstract}

Sorghum (Sorghum bicolor) ergot, caused by the fungus Claviceps africana Freder., Mantle, \& De Milliano, is one of the most destructive diseases of sorghum under favorable environmental conditions. The pathogen only infects unfertilized flowers $(1,9)$, and consequently, once a flower is pollinated, it becomes effectively immune to infection. Hence, hybrid-seed production fields planted to male-sterile lines, which depend on male pollinators for a pollen source, are more vulnerable to ergot than commercial grain production fields planted to self-fertilized hybrids. In hybrid seed production fields, pollen from pollinator lines has to travel some distance before it reaches male-sterile lines for effective pollination, and any factor that interferes with pollen delivery increases the chances of infection (9). For example, lack of synchrony between male and female flowers leaves the ovaries open to infection. Prolonged cool and wet condi-

Corresponding author: F. Workneh

E-mail: f-workneh@tamu.edu

Accepted for publication 20 January 2006

DOI: 10.1094/PD-90-0717

(C) 2006 The American Phytopathological Society tions during flowering are not ideal for effective pollination. In addition, preflowering cold stress affects pollen viability $(2,5)$, predisposing sorghum flowers to infection (15). Therefore, even though pollen management is advocated as the best strategy for ergot control, complete pollination is not always achieved.

Until it was observed in Brazil in 1995, the American continent was free of sorghum ergot $(1,20)$. Long distance spread of the pathogen is accomplished by means of air transport of the spores, primarily secondary conidia (7), or seeds contaminated with sclerotia of the pathogen. Sorghum ergot was detected in the United States for the first time in 1997 and subsequently caused widespread damage in hybrid-seed production fields in the Texas Panhandle $(11,28)$. Since its introduction, the disease caused problems every year in hybrid-seed production fields in the Panhandle, with occasional widespread regional epidemics (27). Year-to-year variation in prevalence of the disease has been attributed to variations in regional weather patterns during sorghum flowering periods (28). Sorghum ergot is reported to require high relative humidity $(\geq 90 \%)$ for optimum development (10) and a temperature range of 14 to $28^{\circ} \mathrm{C}$ with optimum near $20^{\circ} \mathrm{C}$. Little or no disease was reported to develop above $30^{\circ} \mathrm{C}$ (14), but data on minimum relative humidity threshold are lacking.

Yield loss due to ergot is primarily caused by failure of infected ovaries to produce seeds, and as high as $80 \%$ loss due to the disease has been reported (1). In place of seeds, fungal masses (sphacelia) develop in the ovaries, which continuously produce honeydew (6). In addition, the sticky honeydew runs down the stems and leaves, gumming up machinery and impeding mechanical harvest. Seeds coated with honeydew exhibit poor germination (12). There are no commercially available resistant cultivars at present, but there are fungicides that provide satisfactory control (16). However, only propiconazole (Tilt) is currently registered for use in the United States (16).

Currently there is a weather-based ergot prediction model developed for South African conditions (13). The model uses mean daily maximum relative humidity and mean daily maximum temperature 1 to 5 days after flowering in conjunction with mean minimum temperature 23 to 27 days before flowering. Inclusion of minimum temperature in the model is justified based on the fact that preflowering cold stress induces male sterility, affecting fertilization and subsequently predisposing sorghum flowers to infection by $C$. africana $(2,4,15)$. The cold stress takes effect when daily minimum temperatures fall below $13^{\circ} \mathrm{C}$ (15). The number of days before flowering in which the cold stress takes effect appears to be partly dependent on the cultivar used (21). In the Texas Panhandle, daily minimum temperatures seldom fall below $13^{\circ} \mathrm{C}$ during flowering or preflowering periods in July and August. Generally, these 2 months are the warmest, and thus, preflowering cold stress may not be a factor in ergot development in the region. In addition, the South African model was developed using self-fertile sorghum lines, which under normal conditions, are less vulnerable to infection than male-sterile lines in seed production fields.

There is a need for greater understanding of the effect of weather factors on sorghum ergot development in hybrid-seed production fields in the Texas Panhandle. In fact, development of a sorghum ergot predictive model for sorghum production conditions in the United States was highlighted as one of the primary research needs at the global sorghum and millets disease conference held in Guanajuato, Mexico, in September 2000 (18). The pri- 
mary objectives of the current project were to determine the relationships between weather variables and sorghum ergot severity, and to develop a weather-based model for predicting sorghum ergot in the Texas Panhandle.

\section{MATERIALS AND METHODS}

Field plot establishment. In 2003, male-sterile sorghum seeds (cv. A.FA301, dwarf, Richardson Seeds Inc., Vega, TX) were contiguously planted $(185,000$ seed/ha) every 2 weeks in 12 rows $(30 \mathrm{~m}$ in length on $0.76-\mathrm{m}$ centers). Planting began in the middle of May and continued until the end of July to ensure continuous availability of flowers for an extended period during the summer. The field plots were established at the Texas Agricultural Experiment Station at Bushland (Emeny field) and were cultivated and furrowirrigated as needed. Average hourly (recorded every $5 \mathrm{~min}$ and averaged) weather data (temperature, relative humidity, precipitation, wind speed, and radiation) were measured using an onsite weather station equipped with a data logger (Campbell Scientific, Inc., Logan, UT) and collected weekly throughout the duration of the experiment.

Inoculum preparation. An isolate of $C$. africana was obtained from a naturally infected sorghum panicle in the Panhandle and maintained year-round on sorghum plants in the greenhouse. For inoculum preparation, infected sorghum panicles containing fresh honeydew were macerated in distilled-deionized sterile water and screened through a double layer of cheesecloth. Spore concentration (mostly macroconidia) was determined using a hemacytometer under a compound microscope and adjusted to the desired level by dilution.

Field inoculations. Prior to inoculation, fully expanded (but nonflowering) sorghum panicles were covered with paper bags to avoid pollination and natural infection. The bags were removed when approximately $1 / 4$ to $1 / 2$ of each panicle flowered from top to bottom (basipetally) and the nonflowering spikes and spikelets on lower portions of panicles (plus any nonflowering spikelets among florets) were trimmed off. The remaining florets on the upper portion of the panicles then were sprayed with $C$. africana inoculum suspensions until runoff using hand-held sprayers. Three levels of inoculum, $1 \times 10^{4}, 1 \times$ $10^{5}$, and $1 \times 10^{6}$ spores $/ \mathrm{ml}$ were sprayed on 10 to 15 plants each, depending on the availability of uniformly flowering plants. Whenever there were two or more closely situated panicles, only one of them was sprayed to avoid cross contamination. In addition, during each inoculation, spraying always proceeded from the highest concentration to the lowest such that when the higher concentration was being sprayed, panicles to be sprayed with lower concentrations were still covered with paper bags. Inoculations were conducted seven times between 17 August and 7 October to ensure exposure to a range of different weather conditions. Inoculation intervals depended on variability of weather conditions. The panicles were harvested 8 to 13 days after inoculation depending on how quickly the disease developed, which was dictated by the weather conditions. Florets with and without honeydew or sphacelia then were counted to determine the percentage of infected florets per panicle (severity).

The experiment was repeated in 2004 using similar management, inoculation, and data collection procedures except that inoculations were conducted 16 times between 7 September and 19 October to take advantage of the variable weather that existed during the period. Because of the more frequent inoculations, there were greater treatment overlaps than in 2003. Therefore, each plant being inoculated was secluded in a cylindrical tin sheet to prevent cross contamination.

Data analyses and model development. Means of percent florets with ergot from individual plants for each inoculation date and inoculum level were calculated and related to each weather variable using either linear or nonlinear regression. Analysis of variance was conducted using the general linear model (GLM), in which 10 to 15 single plants served as replicates, to determine whether there were interactions among the weather variables, year, and ergot severity. For model development, hourly cumulative departures from maximum temperature and minimum relative humidity thresholds for 12-, 18-, 24-, 36-, $48-$, or 72-h periods after inoculation were determined and regressed against ergot severity using nonlinear regression. Thresholds of $30^{\circ} \mathrm{C}(14)$ and $50 \%$ were used for maximum temperature and minimum relative humidity, respectively.

Initially, a model was developed for each of the time-durations using the 2003 data from Emeny field. Each model then was evaluated using a separate data set (not used in model development) collected from an experiment conducted in a field at a separate location (south section) with center-pivot irrigation system (similar to seed production fields in the region). Predicted ergot severity values from the Emeny field (independent variable) were regressed against observed values (dependent variable) from the south section. The models were compared using values of coefficients of determination $\left(R^{2}\right)$, root mean square error (RMSE), and other indices (Table 1). Each model was further evaluated using the 2004 ergot data set from Emeny field. In addition, residual values from the regression models were standardized (studentized) by dividing the values by their standard errors and plotted against the predicted values to evaluate their goodness-of-fit $(3,4,8)$. The residuals for the models also were tested for normality using the Shapiro-Wilk test (22). All analyses were conducted using SAS software version 9.0 (SAS Institute, Cary, NC).

\section{RESULTS}

In both 2003 and 2004, symptoms (honeydew production) began to develop between 6 and 11 days after inoculations. Honeydew production occurred earlier during warmer days following inoculations than during mild or cool days regardless of inoculum concentration. The average number of florets per panicle on which percent ergot infection was based ranged from 198 to 450. Analysis of the ergot severity for the 2003 and 2004 experiment showed that there were no interactions

Table 1. Indices of goodness-of-fit of sorghum ergot models, based on cumulative departures from temperature and relative humidity thresholds at various time durations after inoculation, evaluated with an independent data set in 2003

\begin{tabular}{|c|c|c|c|c|c|c|c|c|}
\hline Hours $^{\text {a }}$ & Observed $^{\mathbf{b}}$ & Predicted $^{\mathrm{c}}$ & $a^{\mathrm{d}}$ & $b$ & $\operatorname{RMSE}_{(s)} \mathbf{e}^{\mathbf{e}}$ & $\operatorname{RMSE}_{(u)}$ & $R^{2}$ & $P>F$ \\
\hline 12 & 14.54 & 13.13 & 3.78 & 0.82 & 2.92 & 3.06 & 0.94 & 0.0009 \\
\hline 18 & 14.54 & 12.83 & 3.98 & 0.82 & 3.19 & 3.08 & 0.93 & 0.0013 \\
\hline 24 & 14.54 & 11.80 & 3.75 & 0.91 & 3.23 & 2.74 & 0.91 & 0.0020 \\
\hline 36 & 14.54 & 11.55 & -16.58 & 2.70 & 4.74 & 7.67 & 0.72 & 0.0197 \\
\hline 48 & 14.54 & 11.59 & -0.64 & 1.31 & 6.72 & 3.68 & 0.67 & 0.0286 \\
\hline 72 & 14.54 & 12.04 & -2.97 & 1.45 & 10.78 & 2.65 & 0.06 & 0.3154 \\
\hline
\end{tabular}

a Duration of time after inoculation (on which models were based) used to calculate cumulative departures from maximum temperature and minimum relative humidity thresholds $\left(30^{\circ} \mathrm{C}\right.$ and $50 \%$, respectively).

${ }^{\mathrm{b}}$ Observed ergot severity values from the independent data set.

${ }^{\mathrm{c}}$ Ergot severity values predicted by the models.

d $a$ and $b$ are intercepts and slopes, respectively, of regression equations for the respective time durations.

${ }^{\mathrm{e}} s$ and $u$ stand for systematic and unsystematic root mean square error, respectively. 
among year, weather variable, and ergot severity. Therefore, data from each year were pooled for determining the relationship between ergot severity and weather variables. Two of the inoculations in midOctober 2004 were not included in the analysis because of the near-freezing temperatures that took place during that week. Normally, sorghum flowering in the region has long been completed by this time (28). Thus, exclusion of the data does not affect the performance of the models, nor does it introduce any bias.

Ergot severity declined exponentially with increasing inoculation temperature with the $1 \times 10^{4}$ and $1 \times 10^{5}$, and linearly with $1 \times 10^{6}$ spores $/ \mathrm{ml}$ (Fig. 1A to C). Little or no ergot developed with $1 \times 10^{4}$ spores $/ \mathrm{ml}$ above $30^{\circ} \mathrm{C}$. However, with $1 \times$ $10^{6}$ spores $/ \mathrm{ml}$, up to $28 \%$ ergot infection was observed at temperatures above $30^{\circ} \mathrm{C}$. Infection occurred with $1 \times 10^{6}$ spores $/ \mathrm{ml}$ at inoculation temperatures of $34^{\circ} \mathrm{C}$, resulting in measurable disease. Ergot severity increased with increasing relative humidity at inoculation, linearly with $1 \times 10^{4}$ spores $/ \mathrm{ml}$ and curvilinearly with the two higher concentrations (Fig. 2A to C). At 20 to $30 \%$ relative humidity, the severity increased with increasing inoculum concentrations. At this range of relative humidity, up to $53 \%$ of the florets were infected with $1 \times 10^{6}$ spores $/ \mathrm{ml}$ compared with near $5 \%$ ergot with $1 \times 10^{4}$ spores $/ \mathrm{ml}$. Ergot severity was exponentially related to maximum relative humidity with all inoculum levels (Fig. 3A to C). The disease was generally negligible below $90 \%$ maximum relative humidity except for $1 \times 10^{6}$ per $\mathrm{ml}$ spore concentration, where severity ranges of 7 to $32 \%$ were observed at maximum percent relative humidity ranges of low- to mid-80s. However, ergot severity increased dramatically above $90 \%$ relative humidity with all three inoculum concentration levels.

Model development. For the 2003 data, of the six time durations, regression models containing cumulative departures from thresholds of temperature and relative humidity $12-, 18-$, and $24-\mathrm{h}$ periods after inoculation, using $1 \times 10^{4}$ spores $/ \mathrm{ml}$, best explained variations in ergot severity $\left(R^{2}=\right.$ $0.98,0.99$, and 0.95 , and $P=0.0034$, 0.0097 , and 0.00175 , respectively). Models based on these variables also provided the best indices when evaluated with the independent data set from the south section (Table 1). Predicted values of each of the three time durations explained greater than $90 \%$ of the variations in ergot severity in the south section (Fig. 4A and B). Data from the final inoculation at the south section were not included due to obvious contamination associated with wind-driven rain. For this reason, only 6 data points were used in validation of the model based on 2003 data.

Further evaluation of the models with 2004 data separately $\left(R^{2}=0.88\right.$ and 0.89 , for 18- and 24-h durations, respectively; $P$ $<0.0001)$ or pooled with the 2003 data $\left(R^{2}\right.$ $=0.89$ and 0.91 for 18 - and 24 -h durations, respectively; $P<0.0001$ ) indicated that the 18- and 24-h durations were more consistent than the rest of the time durations. The same exponential model developed using the 2003 data also best explained variation in ergot severity for 2004. However, the pooled analysis showed a stronger relationship between the weather variables and ergot severity. In addition, the combined data set corresponded to wider ranges of weather conditions than the 2003 data alone. Thus, models for each of the two
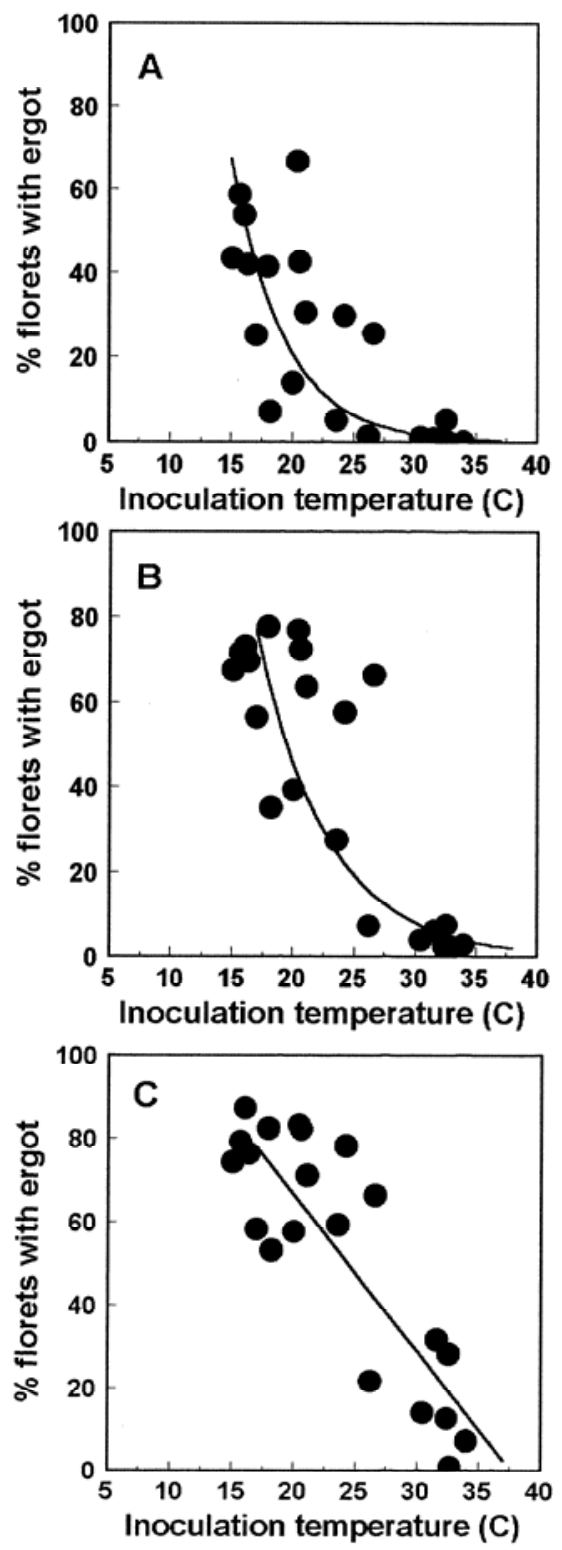

Fig. 1. Relationships between sorghum ergot severity and inoculation temperature in experiments conducted with $\mathbf{A}, 1 \times 10^{4}$ spores $/ \mathrm{ml}[Y=$ $\left.2270 \times e(-0.235 X), R^{2}=0.65, P<0.0001\right], \mathbf{B}, 1$ $\times 10^{5}$ spores $/ \mathrm{ml}\left[Y=1440 \times e(-0.172 X), R^{2}=\right.$ $0.77, P<0.0001]$, and $\mathbf{C}, 1 \times 10^{6}$ spores $/ \mathrm{ml}(Y=$ $\left.142-3.77 X, R^{2}=0.73, P<0.0001\right)$ in experiments conducted at the Emeny field in 2003 and 2004 (pooled). $X$ and $Y$ are temperature and \% florets infected with ergot, respectively. time durations containing temperature and relative humidity were developed using the pooled data. For the 24-h duration, an exponential model

$$
\begin{aligned}
& Y=14.93 \times e\left[-0.0013\left(\sum_{i=1}^{24} X_{1 i}-30\right)\right. \\
& \left.+0.0012\left(\sum_{i=1}^{24} X_{2 i}-50\right)\right]-15.55
\end{aligned}
$$

was developed where $Y$ is percent florets infected with ergot (severity), $X_{1}$ is hourly temperature $(\mathrm{C}), 30$ is maximum temperature threshold (C), $X_{2}$ is hourly percent relative humidity, and 50 is minimum per-
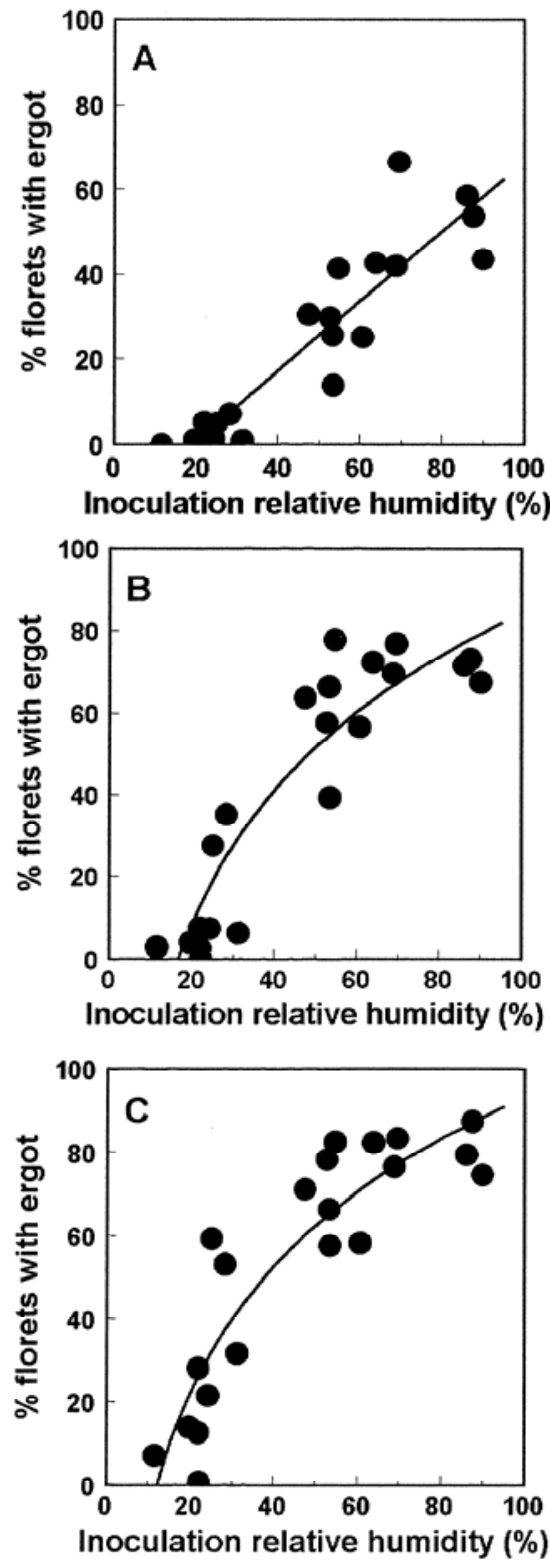

Fig. 2. Relationships between sorghum ergot severity and inoculation relative humidity in experiments conducted with A, $1 \times 10^{4}$ spores $/ \mathrm{ml}\left(Y=-15.5+0.822 X, R^{2}=0.84, P<\right.$ $0.0001), \mathbf{B}, 1 \times 10^{5}$ spores $/ \mathrm{ml}[Y=-133+47.3$ $\left.\times \log (X), R^{2}=0.84, P<0.0001\right]$, and $\mathbf{C}, 1 \times 10^{6}$ spores $/ \mathrm{ml}\left[Y=-110+44.2 \times \log (X), R^{2}=0.81\right.$, $P<0.0001]$ at the Emeny field in 2003 and 2004 (pooled). $X$ and $Y$ are $\%$ relative humidity at time of inoculation and \% florets infected with ergot, respectively. 
cent relative humidity threshold. The same exponential model also was able to describe the 18 -h time durations with variations in coefficients and intercepts. The 18-h duration has an intercept of -31.14 , a coefficient of 31.35 for the base $(e)$, a coefficient of $-5.7 \times 10^{-4}$ and $9.3 \times 10^{-4}$ for temperature and relative humidity (exponents), respectively. Cumulative departures for 12-h duration after inoculation were not consistent (showed substantial reduction in $R^{2}$ ) when used with the 2004 data $\left(R^{2}=0.76\right)$, even though it ranked among the highest in goodness of
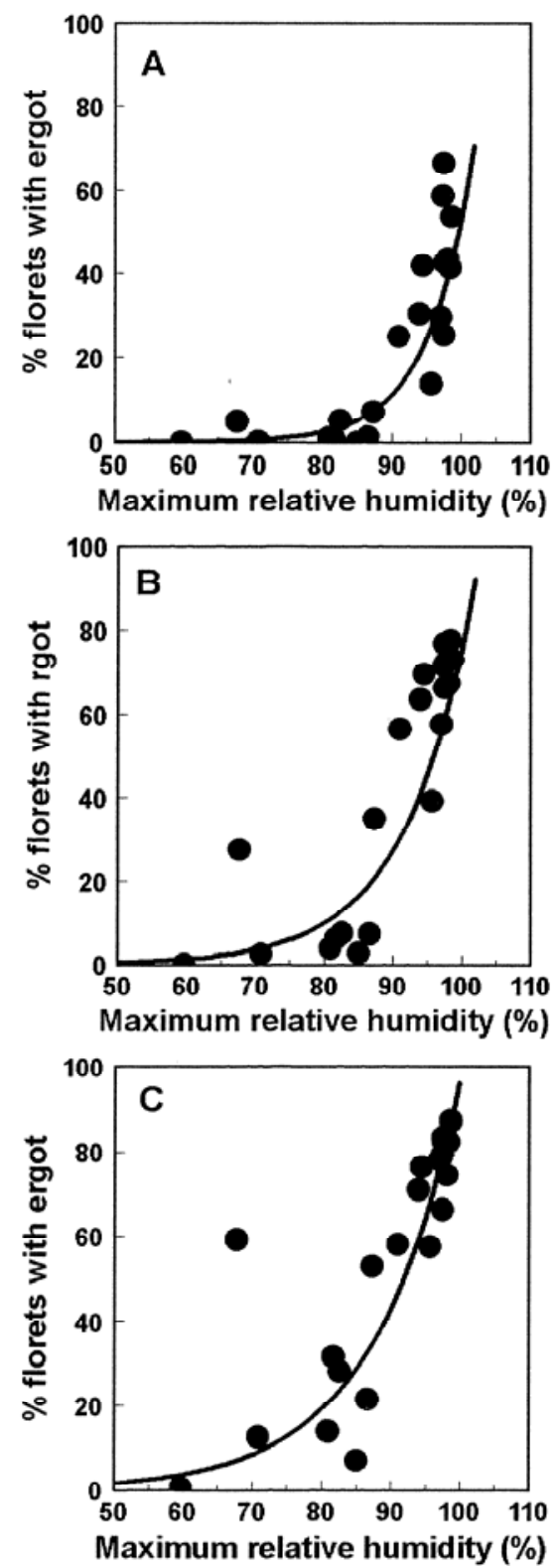

Fig. 3. Relationships between sorghum ergot and maximum relative humidity during artificial inoculation using $\mathbf{A}, 1 \times 10^{4}$ spores $/ \mathrm{ml}[Y=1.12$ $\left.\times 10^{-5} \times e(0.154 X), R^{2}=0.71, P<0.0001\right], \mathbf{B}, 1$ $\times 10^{5}$ spores $/ \mathrm{ml}\left[Y=2.87 \times 10^{-3} \times e(0.102), R^{2}\right.$ $=0.58, P<0.0001]$, and $\mathbf{C}, 1 \times 10^{6}$ spores $/ \mathrm{ml}$ $\left[Y=3.02 \times 10^{-2} \times e(0.0806), R^{2}=0.63, P<\right.$ $0.0001]$ in an experiment conducted at Emeny field in 2003 and 2004 (pooled). $X$ and $Y$ are maximum $\%$ relative humidity and $\%$ florets infected with ergot, respectively. fit when used with the 2003 data (Table 1). Cumulative departures of 36-, 48-, and 72-h periods after inoculations also were not consistent when used with different data sets. Average wind speed during the 24-h period after inoculation had a moderate negative correlation with ergot severity $(r=-0.53 ; P=0.0092)$. Amount of precipitation also had a moderate but positive correlation with ergot severity in 2004 ( $r=0.57, P=0.0221)$ but not in 2003. There was no linear correlation between solar radiation and ergot severity. Addition of both rainfall and wind speed to the 18- and the 24-h duration models did not significantly improve the model attributes.

The distribution of the standardized residuals about the mean value of zero varied between the values of \pm 2.5 (90\% within \pm 2.0 ) for both the 18- and the 24-h models, suggesting that the plots followed the Student's $t$ distribution and there were no outliers $(3,8)$. Results of the Shapiro-Wilk test (22) for the residues revealed that there were no significant deviations from normality $(\mathrm{W}=0.963271, P=0.5843$, and $\mathrm{W}$
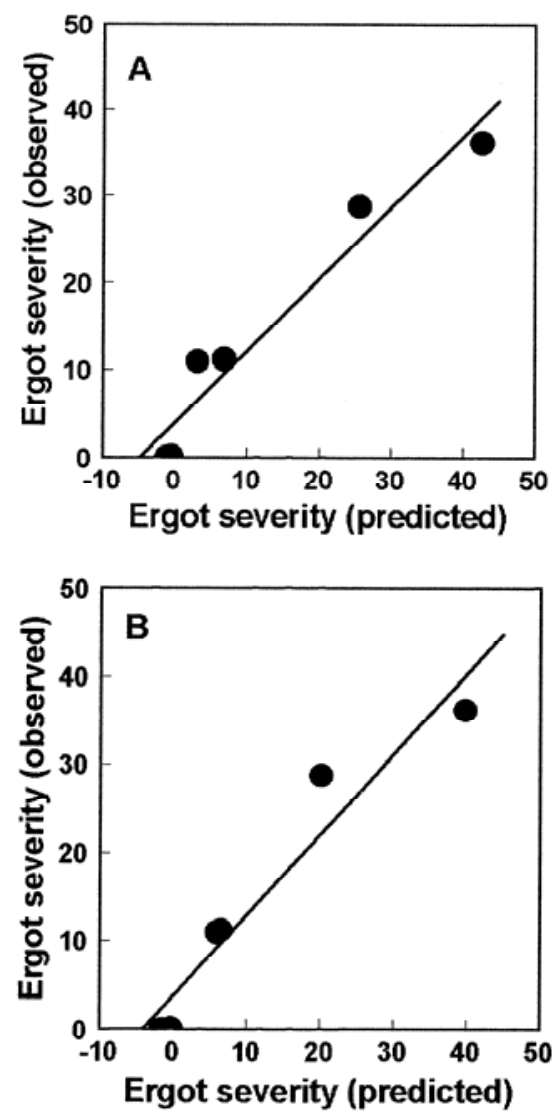

Fig. 4. Relationship between predicted ergot severity values using $\mathbf{A}$, the 18 -h model $(Y=$ $\left.3.98+0.283 X, R^{2}=0.94, P<0.0001\right)$, and $\mathbf{B}$, the 24-h model $\left(Y=3.75+0.91 X, R^{2}=0.93, P\right.$ $<0.0001)$ from the Emeny field and observed severity values from the south section in experiments conducted in 2003 using $1 \times 10^{4}$ spores $/ \mathrm{ml} . X$ and $Y$ are predicted and observed ergot severity, respectively, measured as \% florets affected with the disease.
$=0.959791, P=0.5119$, for the 18 - and 24-h models, respectively).

\section{DISCUSSION}

The 2-year field inoculation study provided important information on the effect of weather factors on sorghum ergot development in the Texas Panhandle. The year 2003 was generally a near-normal year of dry and hot conditions during the sorghum flowering period with occasional showers which provided some cooling effects. However, 2004 was generally cooler and wetter than normal with the exception of sporadic hot and dry interludes. Combining the 2-year data was useful in enabling us to develop models using data collected over a wide range of weather conditions. Relationships between maximum temperature and ergot severity were similar to that of inoculation temperatures and ergot severity for all levels of inoculum because many of the inoculations were conducted late in the afternoon when temperatures were near maximum. Hence, data for maximum temperature are not presented.

Sorghum ergot is typically a cool weather disease with a reported optimum temperature of around $20^{\circ} \mathrm{C}$ and a maximum threshold of 28 to $30^{\circ} \mathrm{C}$ (14). Data on minimum relative humidity threshold are lacking, but a near $100 \%$ relative humidity is considered optimum (10). In our field inoculation experiments, both temperature and relative humidity thresholds appeared to be dependent on inoculum density. Little or no ergot developed above both inoculation and maximum temperature of $30^{\circ} \mathrm{C}$ with $1 \times 10^{4}$ spores $/ \mathrm{ml}$. This is in agreement with McLaren and Wehner's (14) report where they used a lower level of inoculum density. However, it is quite interesting to find that as inoculum level increased, the temperature threshold also increased, and measurable disease was observed at $34^{\circ} \mathrm{C}$ and $1 \times 10^{6}$ spores $/ \mathrm{ml}$. Measurable disease also occurred when relative humidity was 20 to $30 \%$ at time of inoculation using $1 \times 10^{6}$ spores $/ \mathrm{ml}$.

The explanation for the role of spore density may be that in a large population of spores, a few spores may have higher temperature or lower relative humidity thresholds for germination and/or infection. If this is the case, it suggests that $C$. africana may have a potential to adapt to higher temperatures and/or low relative humidity conditions. This may have significant implications for seed production fields in the region, suggesting that sorghum ergot may continue to cause problems in the future even under drier and warmer weather conditions. The natural spore density of $C$. africana in the Texas Panhandle has not been quantified. Use of $1 \times 10^{4}$ spores $/ \mathrm{ml}$ provided consistent results in both years. Even though ergot severity levels comparable to our inoculation results with $1 \times 10^{5}$ and $1 \times 10^{6}$ 
spores/ml have been occasionally observed, we believe that their use in the model may overestimate ergot severity levels in the region. Further studies are necessary using a wider range of inoculum densities than the three levels we used to further elucidate the interaction between weather variables and spore densities of the pathogen in development of ergot.

In addition to spore densities, the duration of favorable or unfavorable conditions after spore deposition may play a significant role in determining infection and the degree of subsequent disease severity. Therefore, accumulated departures from a given threshold of a weather variable are more useful and informative for model development than measurements taken at a single point in time. For this reason, even though there were good curvilinear relations between single-point measurements of both temperature and relative humidity and ergot severity, we used cumulative departures from thresholds of each variable to develop the models. Temperature and relative humidity conditions within 18 - or 24-h periods after inoculation best described variations in ergot severity. This is in agreement with published data that infection can occur within a 24-h period of spore deposition under optimum environmental conditions (10).

In nonlinear models, $R^{2}$ values may not have exact interpretation as in linear models (8). In this manuscript, they are only used as a relative measure to compare different models. Generally, one has to watch for multicollinearity or singularity problems when two highly correlated variables are used in multiple correlation or regression. Multicollinearity effect generally surfaces when correlation coefficients among independent variables are greater than 0.8 or $0.9(23,24)$. In this study, correlation between temperature and relative humidity was -0.67 , and thus, redundancy problems may not be an issue. In fact, it is not uncommon to observe a low temperature and a low relative humidity at the same time in the Texas Panhandle.

Preflowering minimum temperature has been reported to be one of the major factors contributing to sorghum ergot severity even though the preflowering time of critical temperatures varied among previous studies $(13,17,21,25)$. Our study was conducted using a male-sterile sorghum line without a pollinator and thus doesn't incorporate a cold stress factor that could affect pollen viability. Even though preflowering minimum temperature may not be an important factor in the Panhandle, cultural practices and other environmental factors described earlier may have a major impact on ergot severity in the region. Because of these factors, perfect fertilization is impossible and the widespread prevalence of the disease during the past several years supports this view. These factors may need to be considered for in- corporation into an ergot prediction model as a long-term goal.

The source of inoculum for widespread periodic ergot epidemics in the region is not well described. The two ergot models presented in this paper assume that spores of $C$. africana are present in the environment during sorghum flowering periods. This is a valid assumption because spores of the pathogen are reported to survive in infected panicle debris in the region in during the winter (19). However, the magnitude of the impact of the surviving spores on the regional ergot epidemic is unknown. There have been instances of only localized disease incidence even though weather conditions were favorable throughout the region, which may suggest lack of inoculum. In such cases, the models may predict ergot severity based on weather conditions in absence of inoculum in some locations. Conversely, there were incidences of regional periodic ergot epidemics that have been observed simultaneously throughout the Texas Panhandle (27), suggesting the presence of widely distributed spores throughout the region as assumed by the models. It is also speculated that the spores of the pathogen are carried north by air currents from southern Texas or Mexico, where the pathogen is assumed to survive on Johnson grass or other collateral hosts year-round. If the speculation is proven true, results of air parcel trajectory analysis of the spore density should be coupled with the models for better ergot prediction.

The models developed in this study have also been used in prediction of regional site-specific ergot severity potential using radar-estimated rainfall and have shown promising results $(26,27)$. Whenever there was $2.5 \mathrm{~mm}$ of rainfall in the radar rainfall grid, relative humidity in the models was entered as $90 \%$. Otherwise, both temperature and relative humidity in the models were interpolated from the nearest weather station. The 18and the 24-h models predicted ergot severity ranges of 0 to $31 \%$ and 0 to $40 \%$ per panicle, respectively, for the 2002 regional ergot epidemic (27). However, further field validation would be necessary before they are recommended for use in spray advisory programs.

\section{ACKNOWLEDGMENTS}

This project was supported in part by grants from the Texas Higher Education Coordinating Board (ATP) and the Texas Agricultural Experiment Station special initiative on cropping systems. We thank Richardson Seeds Inc. for providing us with seeds of a male-sterile cultivar. We also thank David Jones and Casey Childers for technical assistance.

\section{LITERATURE CITED}

1. Bandyopadhyay, R., Frederickson, D. E., McLaren, N. W., Odvody, G. N., and Ryley, M. J. 1998. Ergot: A new disease threat to sorghum in the Americas and Australia. Plant Dis. 82:356-367.

2. Brooking, I. R. 1976. Male sterility in Sor- ghum bicolor (L) Moench induced by low night temperature. I. Timing of the stage of sensitivity. Aust. J. Plant Physiol. 3:589-596.

3. Brown, D., and Rothery, B. 1993. Models in Biology: Mathematics, Statistics and Computing. John Wiley \& Sons, New York.

4. Campbell, C. L., and Madden, L. V. 1990. Introduction to Plant Disease Epidemiology. John Wiley \& Sons, New York.

5. Downs, R. W., and Marshall, D. R. 1971. Low temperature induced male sterility in Sorghum bicolor. Aust. J. Exp. Agric. Anim. Husb. 11:352-356.

6. Frederickson, D. E., and Mantle, G. E. 1988. The path of infection of sorghum by Claviceps sorghi. Physiol. Mol. Plant Pathol. 33:221-234.

7. Frederickson, D. E., Mantle, P. G., and de Milliano, W. A. J. 1993. Windborne spread of ergot disease (Claviceps africana) in sorghum A-lines in Zimbabwe. Plant Pathol. 42:368377.

8. Freund, R. J., and Little, R. C. 1993. SAS System for Regression. SAS Series in Statistical Applications. 2nd ed. SAS Institute, Cary, NC.

9. Futrell, M. C., and Webster, O. J. 1965. Ergot infection and sterility in grain sorghum. Plant Dis. Rep. 49:680-683.

10. Futrell, M. C., and Webster, O. J. 1966. Host range and epidemiology of the sorghum ergot organism. Plant Dis. Rep. 50:828-831.

11. Isakeit, T., Odvody, G. N., and Shelby, R. A. 1998. First report of sorghum ergot caused by Claviceps africana in the United States. Plant Dis. 82:592.

12. McLaren, N. W. 1993. Effect of sugary disease exudates on germination, seedling development, and predisposition to seedling disease of sorghum (Sorghum bicolor). S. Afr. J. Plant Soil 10:12-16.

13. McLaren, N. W., and Flett, B. C. 1998. Use of weather variables to quantify sorghum ergot potential in South Africa. Plant Dis. 82:26-29.

14. McLaren, N. W., and Wehner, F. C. 1990. Relationship between climatic variables during early flowering of sorghum and the incidence of sugary disease caused by Sphacelia sorghi. J. Phytopathol. 130:82-88.

15. McLaren, N. W., and Wehner, F. C. 1992. Preflowering low temperature predisposition of sorghum to sugary disease (Claviceps africana). J. Phytopathol. 135:328-334.

16. Montes, N., Odvody, G. N., and WilliamsAlanis, H. 2002. Advances in Claviceps africana chemical control. Pages 105-110 in: Sorghum and Millets Diseases. J. F. Leslie, ed. Iowa State University, Ames.

17. Montes, N., Odvody, G. N., and WilliamsAlanis, H. 2002. Relationship between climatic variables and Claviceps africana incidence on sorghum hybrids in Northern Mexico. Pages 111-112 in: Sorghum and Millets Diseases. J. F. Leslie, ed. Iowa State University, Ames.

18. Odvody, G. N. 2002. Recommendations from the ergot working group at the third global conference on sorghum and millets diseases. Pages 73-74 in: Sorghum and Millets Diseases. J. F. Leslie, ed. Iowa State University, Ames.

19. Prom, L. K., Isakeit, T., Odvody, G. N., Rush, C. M., Kaufman, H. W., and Montes, N. 2005. Survival of Claviceps africana within sorghum panicles at several Texas locations. Plant Dis. 89:39-43.

20. Reis, E. M., Mantle, P. G., and Hassan, H. A.G. 1996. First report in the Americas of sorghum ergot disease, caused by a pathogen diagnosed as Claviceps africana. Plant Dis. 80:463.

21. Ryley, M. J., Herde, D. J., Bhuiyan, S. A., Henzell, R. G., and Jordan, D. R. 2002. An overview of biology of sorghum ergot. Pages 141-150 in: Sorghum and Millets Diseases. J. 
F. Leslie, ed. Iowa State University, Ames.

22. Shapiro, S. S., and Wilk, M. B. 1965. An analysis of variance test for normality. Biometrika 52:591-611.

23. Stevens, J. 1986. Applied Multivariate Statistics for the Social Sciences. Lawrence Erlbaum, Hillsdale, NJ.

24. Tabachnick, B. G., and Fidell, L. S. 1989. Using Multivariate Statistics, 2nd ed. Harper
Collins, New York.

25. Wang, E., Meinke, H., Ryley, M., Herde, D., and Henzell, B. 2000. On the relation between weather variables and sorghum ergot infection. Aust. J. Agric. Res. 52:313-324.

26. Workneh, F., Narasimhan, B., Srinivasan, R., and Rush, C. M. 2005. Potential of radarestimated rainfall for plant disease risk forecast. Phytopathology 95:25-27.
27. Workneh, F., Narasimhan, B., Srinivasan, R., and Rush, C. M. 2006. Assessment of regional site-specific sorghum ergot severity potential using radar-rainfall measurement. Plant Dis. 90:704-707.

28. Workneh, F., and Rush, C. M. 2002. Evaluation of relationships between weather patterns and prevalence of sorghum ergot in the Texas Panhandle. Phytopathology 92:659-666. 